\title{
ФИЛОСОФИЯ
}

DOI: 10.17805/trudy.2015.3.6

\section{УНИВЕРСАЛЬНАЯ ЭВОЛЮЦИЯ В ЗЕМНОМ МАСШТАБЕ}

\author{
А. Э. Воскобойников \\ (Московский гуманитарный университет)
}

Аннотация: Автор анализирует взаимосвязи между природными и социальными компонентами единого процесса универсальной эволюции, смену основных типов детерминации, экологическую проблему.

Ключевые слова: универсальная эволюция, коэволюция, социобиология, экологическая культура.

\section{UNIVERSAL EVOLUTION ON THE GLOBAL SCALE}

\author{
A. E. Voskoboinikov \\ (Moscow University for the Humanities)
}

Abstract: The article analyzes the interconnection between natural and social constituents of a single process of universal evolution, as well as a change in major types of determination and the environmental issue.

Keywords: universal evolution, co-evolution, social biology, environmental culture.

Универсальная эволюция соединяет в едином потоке историю космическую, планетарную и общечеловеческую. Значительный вклад в создание ее фундаментальной панорамы вносят космологи, антропологи, социобиологи, генетики, историки. В какой мере эволюционный процесс задается причинной детерминацией (детерминация прошлым), системной детерминацией (детерминация настоящим) и целеполагающей детерминацией (детерминация будущим)?

Историческое развитие природных систем и человеческих сообществ сопровождается последовательной сменой видов преобладающей детерминации (и даже появлением совершенно новых детерминант). Чем выше развита система, тем, во-первых, больше роль ее высших структурных уровней во внутренних взаимодействиях и процессах, а во-вторых, тем больше у нее мера самодетерминации и свободы относительно внешнего мира.

Можно высказать такой тезис (имеющий определенное практическое и теоретическое обоснование): более высокая эволюционная форма (а также более высокий структурный уровень) обязательно содержит в себе 
более низкую, причем, начиная с момента своей достаточной зрелости, в определенной мере трансформирует последнюю и играет определяющую роль в данной целостной системе. Обсуждая несколько иную проблему, В. Франкл высказывался примерно в этом же духе: «Человеческое измерение является высшим по отношению к животному измерению, и это означает, что оно включает в себя и это низшее измерение. Констатация наличия у человека специфически человеческих проявлений и одновременно признание существования у него субчеловеческих проявлений ничуть не проти-воречат друг другу, ведь человеческое и субчеловеческое находятся друг к другу в отношении, так сказать, иерархической включенности, а отнюдь не взаимного исключения» (Франкл, 1990: 339).

Смена доминирующего типа детерминации может иметь для человека как бы три измерения - филогенетическое, онтогенетическое и конкретнособытийное. Разные этапы становления и развития человека (как в филогенезе, так и в онтогенезе) характеризуются разным «соотношением сил» между биопсихическим и социокультурным. И в филогенезе, и в онтогенезе существуют переломные моменты - смена основного типа детерминации, в частности, переход от большей бессознательно-психической детерминации к большей социокультурной детерминации. Речь, конечно, идет о детерминации не всех, а большинства из основных функций.

Как происходит этот переход? Как вообще меняется один основной тип детерминации на другой? Как осуществляется связь высших типов детерминации с низшими, данными в “снятом” виде? Рассмотрим эту проблему в несколько более общей форме. В развивающейся системе низший уровень ее структурной организации генетически первичен по отношению к высшему и детерминирует на первом этапе процессы возникновения и развития более высокого уровня, а также целостное поведение системы. Однако подлинное "созревание" более высокого уровня происходит тогда, когда для него начинается период самодетерминации (“causa sui"), период «самопорождения» (“sui generis"). В результате постепенно начинает возрастать обратная детерминация низшего уровня более высоким и влияние последнего на поведение системы в целом.

Итак, можно выделить три эволюционных этапа:

1) самодетерминация базового уровня; детерминация им нарождающегося более высокого уровня;

2) самодетерминация как базового, так и народившегося более высокого уровня; их взаимное равновеликое детерминирование;

3) самодетерминация более высокого уровня; преобладающая (над обратной) детерминация им базового уровня.

Так могут меняться причинные взаимодействия двух близлежащих уровней структурной организации. Но это, конечно, не какой-то замкну- 
тый и окончательный цикл. Ведь постепенно может народиться новый, еще более высокий структурный уровень, и процесс сменяющихся форм взаимной детерминации возобновится. Картина, конечно, усложняется тем, что на процесс развития влияют не только детерминистские, но и некоторые другие закономерности. Да и сами детерминистские закономерности имеют характер не однозначной, а многозначной причинноследственной зависимости («мультикаузальности»).

Стратегически постепенно возрастает определяющая роль не «диктата прошлого», а «зова будущего»- целеполагания и целереализации, все более и более зависящих от свободного выбора и творческой деятельности самих субъектов. Благодаря эволюционному развитию в природных системах над физической необходимостью постепенно надстраивалась неосознаваемая биологическая целесообразность, а над ней - со временем - осознанное целеполагание. Последнее, развиваясь, восходило от уровня «осознанной необходимости» до уровня все более свободного творческого проектирования действительности.

Учитывая приведенные выше рассуждения, можно попробовать в какой-то мере уточнить «теорию большого скачка» в развитии человека, связанного с появлением сознания. На самом-то деле этот «скачок» был очень растянут во времени и включал по крайней мере два этапа. На 1-ом этапе появились лишь начальные элементы сознательной деятельности и простейшие обработанные природные предметы, используемые в качестве орудий. Это был как бы «стартовый скачок». Процесс первичного становления сознания был очень долгим и во многом самостоятельным эволюционным этапом, на котором сознание характеризовалось лишь некоторыми из своих будущих атрибутивных свойств, а связанные с ним процессы зачастую имели разобщенный характер.

Не менее радикальный скачок совершился тогда, когда произошла «смена власти» в человеческой психике, а именно осуществилась смена доминирующей детерминанты: ею стало к тому времени уже достаточно развитое и системно высокоорганизованное сознание. Первые проблески разума не определяют существование дикого человека; еще очень долгое время они не могут стать господствующими в его животной психике. То же самое можно сказать о зарождающемся свободном выборе, робких зародышевых формах едва пробуждающейся совести и пр. (Сказанное можно отнести и к наиболее развитым высшим животным). Лишь у Homo sapiens sapiens paзум начинает играть жизнеопределяющую роль. Всемирно известный английский антрополог, лауреат Нобелевской премии мира 2004 года Луис С. Б. Лики ввел в употребление очень важное различие между Homo sapiens sapiens (современным человеком с присущими ему психо-социальными свойствами) и Homo sapiens faber (ранним представителем нашего вида, 
который умел уже изготовлять орудия, но не достиг еще достаточного психо-социального развития). Он безусловно прав,считая, что появление “собственно” человека происходило одновременно с зарождением искусства, религии, магических представлений, с совершенствованием речи (этап возникновения отвлеченных понятий - в отличие от “начальных слов”, обозначающих отдельные материальные предметы). Соображения Лики бесспорно верны. Но мне кажется, что точнее было бы выражение не Homo sapiens sapiens, a Homo sapiens culturalis. Ведь это полнее соответствует человеку не только разумно думающему, но и разумно чувствующему и разумно действующему. Отличие людей от животных действительно начало формироваться с появлением производственной деятельности. Однако животная природа доминировала в людях над уникально человеческой еще очень долго - вплоть до появления речи, абстрактных понятий и пр. Кстати говоря, сознательно отличать себя от животных люди начали не раньше этого более зрелого момента своего развития.

Подчеркну еще раз: зрелое сознание, господствующее в психике и определяющее человеческую деятельность, существует пока гораздо меньшее время, чем существовало сознание становящееся. Во время же становления сознания в психике продолжало доминировать бессознательное; именно тогда в прямой и неукоснительной форме действовал принцип «бытие определяет сознание».

Остановлюсь еще на одном, чрезвычайно важном, с моей точки зрения, моменте. В процессе эволюционно-исторического развития человечества (при благоприятных социальных условиях) многообразные позитивные взаимодействия между бессознательным и сознательным не только не уменьшаются, но все больше возрастают. Впрочем это не относится к периодам значительных социальных деформаций и общего упадка культуры. В такие времена отношения между сознательным и бессознательным могут обостряться, в свою очередь существенно влияя как на социальную, так и на индивидуальную жизнь людей. В результате деформируются системы ценностных ориентаций, цели и смыслы существования, а на смену чело-веческой целостности приходит дисгармония человеческой «расщепленности».

Каждый объект «аккумулирует» в себе свою историю. Существенные события, совершившиеся с ним, не исчезают бесследно, а как бы «откладываются» в его структуре. Не только деревья, но и скалы, и звери, и люди, и культуры имеют свои «годовые кольца» (это связано, в частности, с царящими в окружающем мире законами сохранения). Разумеется, настоящее переплавляет отложенное в нем прошлое в новые формы, но полностью не порывает с ним никогда.

Чем выше уровень организации объекта, тем сложнее структурная кар- 
тина, воспроизводящая его прошлое развитие. Эта воспроизводящая структура становится все более динамичной. Она уже воспроизводит прошлое развитие не только через статичную пространственную картину: кроме пространственного в ней появляется и временное измерение; таким образом, воспроизводящая структура из синхронной превращается в синхроннодиахронную. Так, например, в синхронной структуре организма в какой-то мере отражен его филогенез; но гораздо полнее филогенез воспроизводится онтогенезом, так как тот учитывает и временное измерение.

Итак, в структуре той или иной сравнительно высоко организованной системы, в отдельных ее свойствах проявляются пройденные ею более примитивные этапы ее развития. Однако наиболее характерными, определяющими будут для системы не эти более простые свойства и структурные особенности, а новые, приобретенные на высшей ступени развития системы.

С расширением и углублением социальных связей, а также с появлением культуры открываются принципиально новые возможности запечатления и сохранения всего того ценного, что достигается в процессе развития. Благодаря новым коммуникационным системам (и прежде всего вербальному языку) невероятно возрастает объем накапливаемой информации, ее многообразие, полезность и адекват-ность. Существенно меняется и характер поисков новых вариантов для дальнейшего развития. Теперь это не стихийный перебор всех возможностей методом проб и ошибок, а все чаще и чаще сознательная оценка ситуаций, разумный выбор стратегии, осмысленное прогнозирование результатов и т. д. Культура же постепенно развива-ется и активизируется по отношению к историческому процессу: она уже не только аккумулирует опыт, но все больше предопределяет дальнейший ход событий.

Рассматриваемая проблема представляет большой интерес в следующем плане: закономерности исторического развития мышления, закономерности развития мышления индивида и закономерности развития рассуждений при решении конкретных исследовательских задач имеют некоторые общие черты. Это позволяет взаимно контролировать и обогащать исследования в одной из указанных областей соответствующими исследованиями в других областях.

Историко-генетический анализ мышления словно дает замедленную киносъемку целого ряда быстротекущих процессов логического развития мысли. Решая какую-нибудь задачу, изучая впервые какой-то сложный объект, современный человек вначале оказывается в чем-то в таком же положении, как и первобытные люди, впервые изучающие мир (или уподобляется ребенку, начинающему понемногу усваивать окружающее). Во всех этих случаях сперва пользуются самыми простыми понятиями вроде «боль- 
ше - меньше», «дальше - ближе», «целое - часть» и т. д. В этом нет ничего удивительного. Ведь основные этапы познавательного процесса примерно совпадают с основными ступенями формирования психики и сознания.

На биологическом уровне информация кодируется и циркулирует благодаря хромосомным структурам клеток и нейродинамическим структурам мозга. Генетическая наследственность позволяет передавать информацию от одного поколения к другому. Лишь начиная с высших животных в эволюционном развитии появляется возможность - накапливать дополнительный опыт, непосредственно подражая поведению родителей и других ближайших особей. Но еще очень долгое время опыт, накапливаемый отдельной особью, не покидал временные рамки ее поколения. Это, безусловно, заметно сдерживало темпы эволюционноисторического развития.

Культура (в самом широком понимании) - это «очеловеченная» природа (т. е. природа, утратившая свою девственность и вовлеченная в материально-практическую и духовную жизнь людей). В этом смысле «культура» противопоставляется «натуре». На заре человеческой истории появление новых жизненных процедур, создание новых орудий и технологий сопровождались созданием связанных с ними новых знаков, значений и смыслов. Как те, так и другие, будучи чрезвычайно важными для жизни, нуждались в сохранении и ускоренной передаче не только современникам, но и потомкам. Это было невозможно биогенетическим путем. Ведь для закрепления нового социального опыта в биогенетических структурах требовались бессчетные повторения того, что закрепляется, и огромные интервалы времени. Тогда-то и появляется новое социальное измерение - культура, ставшая каналом и хранилищем не только всего привычного, но и неповторимо нового в социальном опыте.

Люди только тогда начинают по-настоящему возвышаться над царством животных, когда привыкают создавать новые орудия, действия и знаки, которые передаются последующим поколениям. Подобная передача изначально опирается на сознание, хотя в дальнейшем может частично приобрести характер неосознаваемого автоматизма. Так зарождается и начинает функционировать Культура. Культура - это, прежде всего, мир человеческой деятельности. Кроме того, она пронизана значениями, смыслами и значимостями (последние выражают ценностные ориентации). Важная роль в функционировании культуры принадлежит правилам и традициям (в том числе и нормам), регулирующим поведение.

Эволюция не только копирует, но и ищет новое. В процессе эволюционного развития возрастает человеческая индивидуальность. Социобиология ${ }^{1}$ опирается на принцип об универсальном значении социальности для всего животного мира, о ее постепенном развитии. Совершенствование 
социальности происходит в результате естественного отбора более жизнеспособных стереотипов совместного поведения. Согласно социобиологическому подходу, самые существенные черты человеческого поведения формировались под воздействием естественного отбора и обусловлены генетическими факторами. Теория «геннокультурной коэволюции» исходит из того, что процессы органического и культурного развития протекают согласованно друг с другом (однако «тон задают» гены).

Одна из естественнонаучных причин оживления социобиологизма в философской антропологии - это прогресс молекулярной биологии, включающий такие важнейшие открытия, как раскрытие механики белкового синтеза, расшифровка генетического кода, что заметно углубило наши знания о жизненных процессах. Роковая ошибка во всех подобных исследованиях совершается в том случае, если, изучая важнейшие биологические и социобиологические процессы, характерные для человека, перестают видеть определяющие его существование надбиологические факторы. Говоря о природе, чаще всего имеют в виду либо природу вообще (весь материальный мир), либо окружающую природу (совокупность естественных условий существования человечества). Во втором случае также принято употреблять выражение “природная среда”. Человек взаимодействует с природной средой на таких уровнях как литосфера, гидросфера, атмосфера, биосфера, космосфера. Природа существует не только вокруг нас, но и в нас самих. Более того, она непосредственно представлена на нескольких уровнях - физическом, биологическом и врожденнопсихическом. Косвенное же ее влияние охватывает всего человека.

Конечно, подобно внешней по отношению к человеку, входящая в его внутренний мир природа находится под все возрастающим воздействием культуры и цивилизации. Но она продолжает подчиняться прежде всего своим собственным универсальным закономерностям, которые просто своеобразно проявляются в заданных цивилизацией условиях. Ведь социокультурное не «отменяет» физическое и биологическое, а как бы надстраивается над ними. Так в свое время биологическое возвысилось над физическим, не устраняя его, а включая в себя (в «снятом» виде).

В истории цивилизации можно выделить три этапа, определяемые характером связей между обществом и природой. На первом этапе существовала полная и неотвратимая зависимость людей от природных процессов. Античными философией и художественным творчеством прекрасно запечатлено, что люди той эпохи неотделимы от природы. Как и многие предшествующие поколения, они продолжали жить, почти полностью подчинив свою жизнедеятельность чисто природным закономерностям. Природу постигали не для того, чтобы властвовать над ней, а для того, чтобы наслаждаться ее красотой и гармонией, а также определить свое место в ней. 
Второй этап характеризуется развитием крупного машинного производства и частнособственнических отношений, которые изменили прежнюю связь: природу стали познавать, чтобы ее изменить, подчиняя собственным нуждам.

На третьем этапе постепенно все больше назревала потребность подходить к природе как к своеобразному целостному образованию («организму»), включающему в себя общество. Стало необходимым рассматривать природу и общество как нечто единое, а стремясь управлять ее стихийными процессами, естественно вписывать в жизнь природы лучшие достижения цивилизации и культуры. Попытки же одерживать побе$\partial ы$ над природой показали всю их ненадежность. Нередко за кажущимся успехом возникали неожиданные последствия, которые сводили на «нет» первоначальное достижение.

То, что подавляющее время своего существования, как вида, люди находились в полной власти природных сил, не вызывает сомнений. Ведь на первом этапе люди совершенно не знали физических, биологических и прочих природных закономерностей, не говоря уже о более универсальных мировых принципах; поэтому они никак и не пытались активно воздействовать на природу (за исключением пассивных действий в форме магических заклинаний или молитвенного обращения к богам). Принудительный (но уже в гораздо меньшей степени, чем в прошлом) характер многих природных воздействий в той или иной форме сохранился до наших дней. Трудно не заметить воздействие природных факторов на такие стороны жизни людей, как питание, жилье, одежда, заболевания, продолжительность жизни, традиции, привычки.

Один из ведущих французских историков Ф. Бродель напоминает о том, что нельзя полностью пренебрегать географическим детерминизмом: «Человек - пленник своего времени, климата, растительного и животного мира, культуры, равновесия между ним и средой, создаваемого в течение столетий, равновесия, которого он не может нарушить, не рискуя многого потерять. Посмотрите на сезонные перегоны овец в горы, характерные для жизни горцев, на постоянство некоторых экономических форм деятельности жителей приморских районов, связанное с биологическими особенностями побережья, взгляните на устойчивость местоположения городов, на постоянство путей сообщения и торговли, на удивительную прочность гео-графических рамок цивилизации» (Бродель, 1997: 124).

Экологическое «общественное мнение» иногда не придает должного внимания тому, что научная типология экологических опасностей глобального масштаба включает не только те, что порождены деятельностью людей, но и те, что связаны с развитием самой природы. Причем некоторые из подобных опасностей могут носить стремительный характер 
(сверхвспышка на Солнце, столкновение с большим астероидом, нарушение равновесных процессов в глубинных недрах Земли, суперэпидемическое заболевание того или иного животного или растительного вида). Конечно, прежде всего следует заботиться о результатах воздействия «своих собственных рук», но важно быть готовыми и к иным, в том числе сравнительно неожиданным катастрофическим природным ситуациям. Лишь тогда удастся в какой-то мере уменьшить трагические последствия от стихийных бедствий.

Однако продолжим анализ изменений, которые постепенно происходили во взаимосвязях между человеком и природой. Наряду с природными воздействиями на людей со временем стало все больше и больше формироваться всевозможных типов взаимодействий между природой и человеком. Более того, постепенно стало возрастать активное воздействие человека на природу, преобразующее ее в человеческих интересах. Ныне человек в принципе способен существовать в самых необычных обстоятельствах и экстремальных ситуациях. Но это требует особо тщательной подготовки. Ярким примером жизни и работы в экстраординарных условиях является длительное пребывание человека в космическом внеземном пространстве.

Чаще всего природные и социальные взаимодействия человека с окружающим миром переплетены между собой. Рассмотрим один из примеров. Наблюдается ускоренное созревание человеческого организма. Для него существуют многообразные объяснения: финалистское (А. Портман, В. Целлер и др.), биологическое (Э. Мартини, Г. Гримм, Э. Кох и др.), селекционное (М. Терек, А. Портман и др.), акселерационное и др. Скорее всего, они дополняют друг друга. Особую роль среди изучаемых причин играют социальные изменения, определяющие совокупность биологических воздействий на организм (увеличение воздействия солнечных лучей, возрастание употребления сахара и витаминов, увеличение нагрузки на нервную систему, вызванное урбанизацией и др. процессами).

Концентрируя свое внимание на эволюции человека и высших форм живого, мы порою в какой-то мере забываем о глобальной эволюции всей природы. А ведь многие мыслители прошлого говорили об этом. Вспомним хотя бы идеи Гете о двух «маховых колесах» природы - принципе полярности (притяжение - отталкивание и пр.) и принципе нарастания (повышение уровня организованности). А из последнего принципа вытекает, что природа всегда существует «в вечно стремящемся потоке», в непрекращающемся возвышении своей духовности.

Такие ценностные ориентации современной культуры как сотрудничество, кооперация, ненасилие, любовь органично связаны с концепцией коэволюционного развития общества и природы ${ }^{2}$. «Общая» коэво- 
люция включает коэволюцию биологических систем, генно-культурную коэволюцию, коэволюцию человеческой психики и духовно-психической жизни социокультурных сообществ, коэволюцию природы и общества, коэволюцию различных концепций и учений и т. п. Коэволюционный подход помогает преодолеть неоправданное отрицание роли биологоантропологических факторов в социокультурной эволюции. Кроме того, он прекрасно согласуется с плодотворной идеей о том, что биологическая эволюция человека не завершилась, как считают многие, примерно 10 тыс. лет тому назад, полностью сменившись одной культурной эволюцией; скорее всего, основные ментальные характеристики мозга продолжают свое развитие. Такой авторитетный исследователь как Э. Уилсон даже выдвигает «тысячелетнее правило» для генетической эволюции мозга, считая, что за 30-40 поколений в человеке происходят определенные социобиологические изменения.

Коэволюционный дух мышления пронизывает не только науки биологического цикла, но все более уверенно входит в геологию, астрономию, космологию, гуманитарные науки. Коэволюция стала заметнее характеризовать и развитие самих внутринаучных принципов и подходов - идет их все большее сближение и взаимопроникновение (и это не просто интеграция различных пластов научного знания, а их взаимопорождение). Лишь при неукоснительном следовании стратегии устойчивого развития возможен новый этап успешной коэволюции человечества в согласии с природой. Эта стратегия признана основополагающей рядом международных конференций и симпозиумов (в Рио-де-Жанейро в 1992 г.; в Амстердаме и Москве в 1996 г.).

K сожалению, человеческая способность действовать постепенно стала все больше обгонять возможности предвидеть последствия своих действий. Как известно, ныне воздействие человечества на нашу планету соизмеримо уже по мощи с космическими факторами. При преобладании отрицательных коэволюционных моментов над положительными появляется зловещая опасность как для окружающего мира, так и для самих людей. Вот почему сегодня над выживанием всего рода человеческого нависла неумолимая угроза. Индивидуальная «пограничная ситуация» переросла в XX веке в общечеловеческую. Перспективы развития человека следует рассматривать в широком контексте биосферных, ноосферных и космических взаимодействий.

Необходимость решать встающие в связи с этим проблемы привела к стремительному росту такой науки как экология. Она изучает воспроизводство жизни, первостепенно учитывая важнейшую роль гео-, биосоциальных факторов этого воспроизводства. Уже Штайнер в своей антропософии предчувствовал необходимость единения с природой на новом 
витке исторического развития; а А. Швейцер мудро и точно определил абсолютное ценностное основание человеческой жизни - благоговейное отношение ко всему живому. Но подлинное массовое прозрение пришлось на 60-е годы XX века, когда началась настоящая революция в умах, появилось движение зеленых, стремление к упрощению жизни. Гимном поколения Вудстока стала песня Джонни Митчелл с такими словами: «Мы вернемся к земле и освободим наши души от грязи больших городов». В ряде стран были созданы экологические политические партии; стали функционировать полицейские спецподразделения по охране окружающей среды, оснащенные необходимой аппаратурой и оперативно выявляющие «экологические преступления». Формирование более зрелого экологического сознания, а также развитие крепнущего экологического движения, охватывающего все новые страны и регионы, говорят о смене определенных важных мировоззренческих ориентаций. Таким путем понемногу преодолевается непростительная экологическая неграмотность довольно широких слоев населения.

В нашей стране в начале перестройки заметно обострились чувства человеческого достоинства и ответственности, а также немыслимое без них экологическое сознание. Но в последние годы экономические и политические мотивации потеснили его на периферию обыденнообщественного сознания. В действиях аппарата чиновников, руководителей и хозяев предприятий, да и самого правительства преобладают иные настроения, суть которых сводится к тому, что сейчас-де не до забот о природе. В погоне за максимальными прибылями предприниматели нередко используют такие технологические новшества, которые пагубно влияют на окружающую среду. Но любая хозяйственная деятельность, игнорирующая нравственные и экологические нормы, становится разрушительной и опасной не только для природы, но и для самих людей.

Важно не только добиваться расширения и углубления экологических знаний, но и того, чтобы они приводили к появлению соответствующих социальных потребностей и становились регулятором практической деятельности. Важнейшие из них представляют так называемые «экологические императивы» - социальные и моральные нормы взаимоотношений человека и природы. Некоторые из них в броской и лаконичной форме попытался сформулировать Б. Коммонер: «Все связано со всем», «все должно куда-то деваться», «ничто не дается даром» и др. (Коммонер Б., 1974: С.32.) Из них напрашивается вывод: со всех точек зрения (включая экономическую) целесообразнее не загрязнять окружающую среду, чем разрабатывать и внедрять сложнейшие дорогостоящие технические устройства, которые ее очистят.

Экологическая культура ориентирует на целостное, холистическое 
воспроизведение мира. В очень скором времени - хотим мы этого или не хотим - экологическая проблема станет во главе угла и в экономике, и в политике. Но пока многие актуальные экологические задачи упираются в цепочку государство - рынок - гражданское общество. Наличие надежной и эффективной государственной структуры является важнейшим условием налаживания охраны окружающей среды. К сожалению, в определенных кругах распространен ложный стереотип, в соответствии с которым природоохранные мероприятия якобы препятствуют экономическому развитию. Слабость экологического законодательства во многих странах обусловлена тем, что законы в скрытой форме больше оберегают интересы промышленных монополий, чем многострадальную окружающую среду. Что касается средств массовой информации, то они поднимают экологические вопросы чаще всего тогда, когда возникает сенсационная катастрофа.

На протяжении многих веков производственно-экономическая деятельность человечества была ориентирована на прибыль и удовлетворение потребностей без учета последствий для природы. Ныне стал неотложным переход производственно-экономической деятельности на новые рубежи: в стоимость любой продукции следует включать затраты на возмещение ущерба, приносимого природной среде (в перспективе желательна ориентация на полное восстановление гомеостатического равновесия, которое существовало до производственного «вмешательства» в природные процессы).

Экологические программы могут быть эффективными только при соответствующем действенном природоохранном законодательстве, позволяющем привлекать к персональной ответственности тех, по чьей воле создаются и осуществляются опасные проекты, вызывающие серьезные нарушения экосистем.

Наша цивилизация подошла к черте, за которой уже недостаточны не только современные знания, но и распространенные ныне моральные нормы и системы ценностей. Развиваться дальше станет возможно лишь воссоздав равновесие между жизнью общества и биосферой, восстановив их коэволюцию. Развиваться не за счет природы, а вместе с ней - таков императив нашего времени. Во имя этого социальное целеполагание не должно вступать в роковое противоречие с природной целесообразностью.

\section{СПИСОК ЛИТЕРАТУРЫ}

Бродель, Ф. (1997) История и общественные науки. Историческая длительность // Философия и методология истории. М. : Прогресс. С. 115-142.

Коммонер, Б. (1974). Замыкающийся круг. Л.: Гидрометеоиздат.

Луков, Вал. А. (2011) Биосоциология // Знание. Понимание. Умение. 
№ 3. C. 319-323.

Моисеев, Н. Н. (1993) Восхождение к Разуму. Лекции по универсальному эволюционизму и его приложениям. М. : ИздАТ.

Моисеев, Н. Н. (1998) Судьба цивилизации. Путь разума. М. : Изд-во МНЭПУ.

Моисеев, Н. Н. (1994) Современный антропогенез и цивилизационные разломы (эколого-политологический анализ). М. : Изд-во МНЭПУ.

Франкл, В. (1990) Человек в поисках смысла. М. : Прогресс.

Примечания:

${ }^{1}$ Сопоставить социобиологию и биосоциологию поможет информационно емкая статья Вал. А. Лукова (Луков, 2011). Мне кажется, что в данном случае совпадает конечный объект исследования, а различаются в известной мере исходные ракурсы - биологический или социологический.

${ }^{2}$ Как глубокое научное, так и нравственное содержание коэволюционной концепции выделял в многочисленных работах академик РАН Н. Н. Моисеев (Моисеев, 1993, 1994, 1998).

Воскобойников Анатолий Эммануилович - доктор философских наук, профессор кафедры философии, политологии и культурологии Московского гуманитарного университета. Адрес: 111395, Россия, г. Москва, ул. Юности, д. 5. Тел.: +7 (499) 374-81-61. Эл. адрес: laer_tino@mail.ru

Voskoboinikov Anatoliy Emmanuilovich, Doctor of Philosophy, Professor, Department of Philosophy, Culturology and Politology, Moscow University for the Humanities. Postal address; 5 Yunosti St., 111395 Moscow, Russian Federation. Tel.: +7 (499) 374-81-61. Email: laer_tino@mail.ru 